\section{AS FUNÇÕES ESTÉTICAS E IDEOLÓGICAS DO CATÁLOGO NA ENEIDA VII}

\author{
Felipe Vale da Silva* \\ Sabrine Ferreira da Costa**
}

RESUMO: O presente artigo parte da consideração do uso peculiar do catálogo em Virgílio, levando em conta sua apresentação em modelos precedentes e posteriores do gênero épico, ao investigar a função deste recurso no livro VII da Eneida. Propõe-se que o catálogo desempenha uma função dupla intimamente ligada ao tema central do poema. Virgílio se vale daquele como estratégia de defesa da ideologia imperialista augustana, ao passo que manuseia em favor deste propósito a experimentação de um modelo renovado de fazer poético, pautado em ideais clássicos de beleza e simetria. Nesta conjuntura, a personagem Camila manifesta-se como figura modelar, pelo que terá suas características esmiuçadas no desdobramento final deste trabalho.

PALAVRAS-CHAVE: Eneida; catálogo; poesia épica; literatura augustana; guerreira Camila.

\section{ON THE AESTHETIC AND IDEOLOGICAL FUNCTIONS OF THE CATALOGUE IN AENEID VII}

\begin{abstract}
This paper sets out to dispose the peculiar employment of the catalogue in Virgil, taking into account the presence of such an important element in both previous and posterior models of epic poetry and thereby focusing on the employment of this device in book VII from the Aeneid. The underlying proposal of the article is that Virgil's catalogue plays a double function, intimately connected to the central subject of his poem: it is employed as a way to endorse Augustan imperialistic ideology and to experiment with a renewed model of poetic creation based upon the classical ideals of beauty and symmetry. In this sense, the character Camilla can be deemed as a model figure, and thus will be analyzed in detail at the end of the article.
\end{abstract}

KEYWORDS: Aeneid; catalogue; epic poetry; Augustan literature; warrior Camilla.
* Doutor em Letras

(Alemão) pela

Universidade de São

Paulo.

felipe.vale.silva@

gmx.com

** Graduação em

Letras (Francês) pela

Universidade de São

Paulo.

sabrine.costa@usp.br 
$\mathrm{O}$ catálogo é uma parte constitutiva da épica tradicional; ele serve a uma função específica dentro da economia do texto que tem sido discutida desde a Antiguidade até, pelo menos, o Classicismo de Weimar, já em meados de 1800. Nesse sentido Williams (1961, p. 146) interpreta o catálogo como uma peça essencial do "maquinário" épico, e o faz com razão.

Não obstante, certas dificuldades surgem quando partimos de um dado curioso: nos exemplos mais célebres de poesia épica no percurso da literatura ocidental, os objetos catalogados são diversos; eles variam de povos em embarcações (Ilíada), passando por líderes tribais italianos (Eneida), chegando até mesmo a legiões de demônios (Paradise Lost de Milton) e espécies de árvores (The Faerie Queene de Spencer). ${ }^{1}$ Há na tradição, portanto, uma singular liberdade de escolha dos objetos de catalogação que força seus intérpretes a considerar dois fatores:

(1) Qual é o sentido do objeto elencado na economia do texto-em outras palavras, que tipo de valores representam e buscam negociar com seu público?

(2) Qual é a função do catálogo em si em relação ao todo do texto em que figura - em que parte do texto ele se insere, como se relaciona com outros episódios, qual é sua função dentro da dinâmica narrativa?

Respostas diversas foram dadas a alguns dos catálogos mais renomados do cânone. R. D. Williams (1961, p. 146) justificou o de Apolônio, por exemplo, como uma introdução ao tipo de texto que viria adiante; o fato de inseri-lo logo no início de seu poema, diz o autor, parece apontar para um tipo de catálogo desvinculado da economia do texto, meramente ornamental, ou ainda uma forma de demonstrar conhecimento e, assim, legitimar o texto para sua comunidade de leitores eruditos. Outros catálogos carregam valor explicitamente ideológico: Homero foi aquele que expôs um catálogo de embarcações, cada qual ligada a uma cidade-estado, sob pretexto de defender a coesão da Magna Grécia, incluindo os mais diferentes povoados falantes de grego em uma unidade político-cultural coesiva.

Todos esses dados são aparentemente dispersos, mas não são de todo improfícuos para formularmos o ponto de partida de nossa argumentação: a função de cada catálogo em cada texto épico deve ser analisada em sua singularidade, uma vez que a técnica de catalogação em si é complexa.

Este será o ponto de partida para a análise que se segue do uso da técnica em Virgílio, tendo como foco, sobretudo, o catálogo presente no livro VII da Eneida (vv. 645-817). Inicialmente compará-lo-emos a outros catálogos da tradição épica anterior e posterior, destacando seus traços gerais, posição no poema e relação com o tema central. A tese primária deste artigo partirá da hipótese de que o catálogo em Virgílio serve a dois objetivos bastante

\footnotetext{
${ }^{1}$ A poesia catalogal - a qual podemos associar ao princípio de que é descomplicado engendrar poesia versando sobre temas poéticos, laborioso é transformar matéria não poética em poesia - foi sobejamente usada pelo que conhecemos hoje por poesia didascálica: Trabalhos e Dias e Catálogo das Mulheres de Hesíodo, bem como Fenômenos de Arato e Veneno dos animais de Nicandro são alguns exemplos modelares do gênero.
} 
coerentes com o tema da Eneida: primeiramente, ele defende uma ideologia imperialista e a ideia de que Eneias, o patriarca dos romanos e ancestral de Augusto, estava predestinado a conquistar a região da Hespéria. Para fundamentar este ponto utilizaremos, sobretudo, as abordagens de viés histórico de Gransden (2004) e Panoussi (2010). O segundo alvo do catálogo diz respeito à sua função estética ou poética. Há maior simetria na construção catalogal da Eneida do que em outros textos da tradição, e, baseados em Williams (1961) e Boyd (1992), argumentaremos que isso se deve a um uso programático de imagens e técnicas narrativas por parte de Virgílio. Um exemplo privilegiado para explicarmos ambas as funções do catálogo será o da guerreira volsca Camila, cujo exame detido dará desfecho a esta análise.

Comecemos pela diferença central entre Virgílio e outros catalogadores: em seu catálogo a ordem dos objetos listados tem sua razão de ser; este não parece ser o caso da Ilíada, em que Homero lista vinte e nove grupos de naus dos aqueus, assomadas a dezesseis grupos dos troianos. Dentro desses dois grupos, a ordem é algo aleatória. O catálogo traz incongruências relativas aos demais cantos, o que leva, ademais, alguns estudiosos a considerá-lo interpolação tardia. ${ }^{2}$

Virgílio, por sua vez, inova no uso da técnica ao aplicar o princípio romano de simetria artística num momento por excelência caótico da épica. ${ }^{3} \mathrm{~A}$ posição de seu catálogo no texto é de suma importância: à primeira vista, ele foi inserido em um ponto avançado, mais ou menos em sua metade, diferente do habitual das grandes épicas antigas. Na Ilíada, por exemplo, o recurso aparece no canto II, vv. 484-761; nas Argonáuticas, o 'catálogo dos argonautas’ surge logo no início, em I, vv. 20-228. Ademais, ao invés de receber uma seção exclusiva para si, o catálogo é disposto na segunda metade do livro VII, como continuação de uma sequência vertiginosa de eventos: Eneias chega ao Lácio; Ilioneu propõe aliança ao hospitaleiro rei Latino, o qual por conta dos fados está decidido a conceder a mão de Lavínia a Eneias; Alecto, a mando de Juno, intervém nos eventos de modo a retardar novamente o triunfo do filho de Vênus; Amata, partidária de Turno, espicaçada pela Fúria, faz oposição aos troianos; um cervo é ferido por Iulo, e as hostilidades que darão abertura para a seção bélica da obra têm início. Observe-se que as contingências se desenrolam no momento da narrativa em que os viajantes atingem sua "terra prometida" (nas palavras de Gransden, 2004, p. 71), após terem passado por diversas provações no trajeto de Troia ao Lácio.

O livro VII, portanto, é um dos momentos cruciais de transição do povo troiano, de sua transformação em povo romano, ${ }^{4}$ e é justo nesse momento de clímax que Virgílio

\footnotetext{
${ }^{2}$ Por exemplo, o espartano Menelau, no catálogo, é proveniente de Micenas. Além disso, os primeiros a ser nele mencionados são os beócios, figuras secundárias na obra como um todo. Ver referências em Mark, 2005, p.10 et seq.

${ }^{3}$ Williams (1961, p. 149) enxerga nessa manobra o melhor uso da técnica de variatio por parte de Virgílio. ${ }^{4}$ No livro VI, Eneias é pela primeira vez chamado de romano; após ser 'reconstruído' enquanto guerreiro ao longo dos seis primeiros livros da obra, e conquistar seu estatuto de herói, ele morre simbolicamente enquanto troiano, e renasce (i.e., retorna do inferno para o mundo dos vivos) um novo homem. O livro VII prenuncia a mesma transição para os demais membros de seu exército, dessa vez por meio da conquista na guerra que devirá.
} 
insere um catálogo, técnica que na Eneida parece ter uma função por excelência retardadora da dinâmica épica. No que seria o primeiro texto épico modelar para a tradição ocidental, i.e., a Ilíada, a catalogação é e deve ser um momento de monotonia, uma espécie de pausa para negociação, um acerto de contas com a comunidade que ouve o poema. Virgílio, em sua épica, estaria fazendo uso da função retardadora a seu favor, estabelecendo-a de modo a servir a dois objetivos: um ideológico e um estético. Os itens seguintes do trabalho explorarão cada um deles.

Há certa importância no objeto catalogado na Eneida: nele, deparamo-nos com a listagem de um "amontoado de clãs" (a gathering of clans, na formulação de Fowler, 1916, p. 26 et seq) que forma um bando semibárbaro, semimítico, numa representação da antiga Itália, destinada a se misturar com o sangue troiano e, no futuro, formar-se como o glorioso Império Romano (Gransden, 2004, p. 87). Embora o catálogo se ordene por treze seções principais - cada uma delas centrada na descrição de representantes tribais -, ele cria um quadro muito mais amplo que nos revela detalhes preciosos sobre modos de vida, formas de se portar e vestir dos povos que habitavam a região.

Mais de um crítico propôs uma interpretação da simetria interna da passagem: Williams (1961, p. 150) sugere que o narrador inicia no campo mítico: as figuras iniciais como Aventino, Cátilo e Coras ${ }^{5}$ estão todas ligadas à mitologia greco-romana. Elas, por assim dizer, compartilham de um universo mágico bastante diverso das sequentes: a partir da descrição de Cátilo e Coras até Umbrão, lidamos com o mundo real de heróis italianos. Esta é a seção do texto com maior número de detalhes etnográficos e geográficos, em que são mencionadas figuras sobre as quais ainda temos material documental confiável. ${ }^{6}$ Após esse longo excurso, o narrador retorna ao campo poético, tratando de Turno (o herói mítico que encabeçará a liga contra Eneias) e Camila, a quem voltaremos a seguir. Por fim, mesmo que o narrador exponha uma infinidade de ideias e de detalhes pictográficos, a unidade do texto não se perde: Virgílio está, antes de tudo, lidando com o tema central de seu poema, apresentando a infinitude de forças inimigas contra as quais Eneias teve de lutar para que a Roma de Augusto, vislumbrada no livro VI, pudesse surgir.

Seu catálogo, assim, é plenamente coerente com a preparação do texto para sua segunda metade bélica. Há um consenso crítico desde a Antiguidade de que Virgílio, na Eneida, integra a narrativa de (des)venturas odisseica e a mavórtica iliádica; o início do livro VII valeria justamente como um divisor de águas na obra (Gransden, 2004, p. 31), além de notabilizar o que seria seu escopo, nas palavras de Virgílio (livro VII, vv. 44-45): "Maior empresa acometo, mais digna de ser decantada / em todo o tempo (...)".7 O narrador, conquanto o sublinhado, vai além de criar uma divisão dentro da obra: em seu catálogo lemos também uma genealogia do povo romano desde o período anterior à glória de Roma. Certamente há na cena muito da mostra de erudição cara aos poetas alexandrinos; como

\footnotetext{
${ }^{5}$ Todos os nomes de personagens e citações da Eneida em português aqui apresentados provêm da tradução de Carlos Alberto Nunes (2014 [1981]).

${ }^{6}$ Ver detalhes em Williams, 1961, p. 151-152.

${ }^{7}$ maior rerum mibi nascitur ordo, / maius opus moveo.
} 
eles, Virgílio esbanja de "conhecimento antiquário, conexões etnográficas e associações etiológicas entre o passado e presente” (Williams, 1961, p. 148). ${ }^{8}$ Mas é importante não perder de vista que o autor também defende interesses específicos que se deixam ver, entre outros artifícios, emblematicamente; por mais simpatia que haja em seus relatos de costumes estrangeiros, estamos diante dos mesmos estrangeiros que foram e deveriam ser conquistados por Eneias e seus herdeiros (cf. Boyd, 1992, p. 214). A infalibilidade do sucesso do herói e seu séquito é parte da ideologia tipicamente imperial da Roma de Augusto, da qual Virgílio foi um representante.

À frente, lidemos com a sina pessoal do herói. Uma passagem da Ilíada (canto XX, v. 293) prognosticou a sobrevivência do jovem Eneias, sem deixar claro como exatamente seria seu futuro. A ínclita manobra de Virgílio consiste em aproveitar a lacuna fazendo da personagem o ancestral mitológico dos romanos. Para tornar a tarefa possível, o autor recupera o guerreiro então fragilizado por uma derrota prodigiosa, leva-o ao autorreconhecimento (Eneida, I, vv. 450-493), para, enfim, após o próprio Eneias anuir que "sinais encontrou / de certeza de que seus males estavam no fim e que lícito lhe era / alimentar esperanças de sorte melhor no futuro" (vv. 450-452), ${ }^{10}$ desenlaçá-lo do passado já preparado para assumir seus encargos como líder de uma jovem nação. No livro VII (vv. 1 et seq), Eneias enterra Caieta, sua ama de tempos de menino. Essa morte carrega um valor simbólico por cindir os últimos vínculos entre Eneias e sua infância troiana, ao mesmo tempo em que ocorre no território da Itália. Isto é dizer: assim que pisa na terra prometida, o herói perde o elemento derradeiro que o ligava à terra natal. Esse momento da narrativa, portanto, "salienta o status transicional do herói de um mero indivíduo para o fundador de uma nova nação" (Panoussi, 2010, p. 58). ${ }^{11}$

Em sua alocução ao rei Latino, Ilioneu enuncia fazer parte da comitiva de um líder semidivino. Consideremos os seguintes versos:

\footnotetext{
8 “[...] antiquarian lore, ethnographical connexions, and aetiological associations between the past and the present".

${ }_{9}$ Quando falamos da ideologia imperial da Roma augustana, referimo-nos à toda uma cultura composta por textos e representações pictográficas do imperador que visavam afirmar sua divindade e, consequentemente, justificar seu projeto militar-expansionista. A ideia era que Augusto, como governante, não só sabia o que estava fazendo, como também era agente necessário do plano grandioso que os deuses reservavam a Roma. É característico dessa cultura a construção da imagem pública do imperador "a partir das investiduras que conquista com seu cursus honorum. Suas atividades civis, militares, políticas e religiosas irão [...] determinar um tipo específico de representação, que, somadas ao fim de seu governo, produzirão um acúmulo de figurações que só poderão ser sintetizadas com a divinização.” (Martins, 2011, p. 179).

${ }^{10}$ Tradução a partir de: Hoc primum in luco nova res oblata timorem / leniit, hic primum Aeneas sperare salutem I ausus, et adflictis melius confidere rebus.

11 “[it] underscores the hero's own transitional status from a mere individual to the founder of a new nation".
} 


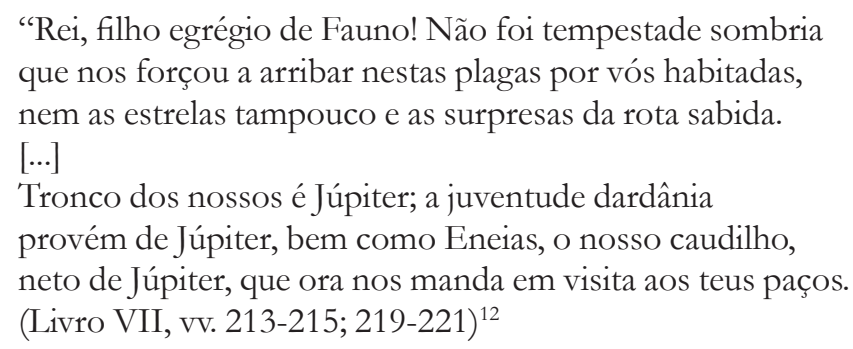

Simultaneamente, Eneias é um ícone que remete ao futuro Império Romano como um todo. Do início ao fim da Eneida, a batalha dos troianos sobreviventes carrega contornos histórico-políticos (ela, afinal de contas, resulta na derrota da população aborígene italiana que preparou terreno para Roma), mas não devemos postergar que é instaurada inicialmente dentro do plano divino. Lemos no mesmo livro VII, vv. 236-240:

Não nos repilas por virmos com vendas nas mãos e aparência
de suplicantes, pois povos sem conta, nações poderosas
manifestaram desejo insistente de a sorte igualarmos
num só destino. Porém a palavra divina nos manda
estas paragens buscar $[. . .]^{13}$

Mesmo os deuses entendem aquele grupo como uma unidade política; é Juno quem afirma: "eu, soberana dos deuses, [...] há tantos anos guerreio um só povo" (livro I, vv. 4648), ${ }^{14}$ embora o faça obter os resultados que deseja. Durante a saga, ela mobilizará deuses menores ou maiores em busca de retardar o destino afortunado do povo troiano, uma vez que não pode revertê-lo. Mesmo quando suas investidas fracassam, ela termina por recorrer a poderes inferiores: uma fúria saída dos infernos, Alecto, é convocada para motivar um exército inimigo representado por Turno contra os troianos. "Já que no céu nada alcanço, recorro às potências do Inferno" (livro VII, v. 312). ${ }^{15}$ Juno deixa de ser uma divindade capaz de contribuir para a ordenação do universo encantado da religião olímpica, para se tornar uma figura impotente perante uma força maior. É o destino, afinal de contas, e não um

\footnotetext{
${ }^{12}$ [...] 'rex, genus egregium Fauni, nec fluctibus actos / atra subegit biems vestris succedere terris, / nec sidus regione viae litusve fefellit: / [...] ab Iove principium generis, Iove Dardana pubes / gaudet avo, rex ipse Iovis de gente suprema: / Troius Aeneas tua nos ad limina misit.

${ }^{13}[. .$.$] multi nos populi, multae (ne temne, quod ultro / praeferimus manibus vittas ac verba precantia) / et petiere$ sibi et volvere adiungere gentes; / sed nos fata deum vestras exquirere terras / imperiis egere suis. [...]

${ }^{14}$ Ast ego, quae divom incedo regina, [...] bella gero!

${ }^{15}$ [...] flectere si nequeo superos, Acheronta movebo. É interessante o episódio de Paradise Lost de Milton (canto 1, v. 263), em que o próprio Satã ecoará as palavras de Juno: "better to reign in hell than serve in heaven". Milton, o qual conhecia bem Virgílio, tem uma compreensão de Juno como antagonista fadada a perder no jogo do plano do destino, exatamente como Satã está inquestionadamente destinado à derrota desde o início da narrativa mitológica cristã. Ambos os trechos, adicionalmente, ecoam a famosa passagem da véxuı $\alpha$ em Odisseia XI, vv. 556-558.
} 
deus do Olimpo, que cooperará para o sucesso do herói épico e para a subsequente glória romana. A manobra de Virgílio se vale da religião olímpica e suas convenções, ainda que termine por defender uma versão de filosofia da história que postula Roma como o destino promitente da civilização.

A função do catálogo no texto não se reduz à defesa de uma ideologia, uma vez que traz um aspecto estético inovador para a tradição épica. Virgílio trabalha elegantemente na descrição de cenas, personagens e geografia, contando com uma técnica em especial que destacaremos aqui, para a qual Williams (1961, p. 147) ${ }^{16}$ emprega um conceito moderno de cinematografia ao afirmar que "o olho do poeta é como uma gravação editada de uma câmera de cinema". Tal dispositivo colabora na realização de um efeito estético inovador: diferentemente de Homero, Virgílio utiliza todos os métodos de apresentação gráfica e pictórica, controla o uso de símiles e evita repetições excessivas, a fim de compor um todo harmônico numa concepção de livro.

Detenhamo-nos na descrição da aparatosa guerreira dos volscos, Camila, que se estende entre os versos 803-817 do livro VII da Eneida:

Vem depois destes Camila guerreira, das gentes dos volscos, capitaneando gentis combatentes. O fuso e as agulhas, dons de Minerva, jamais se lhe viam nas mãos delicadas; endurecera-as nos duros trabalhos dos campos de guerra, pronta a vencer na carreira até os ventos de rápido curso. Era capaz numa seara de voar sobre as louras espigas sem lhes tocar ao de leve ou abater sua bela postura; de atravessar o mar vasto suspensa nas túmidas ondas, sem nele as plantas tocar de mansinho nas cristas umentes. A juventude garrida e as mães velhas à porta corriam para admirá-la à passagem, pasmados de sua elegância, sem dela a vista apartar: como o manto de púrpura os ombros tão delicados lhe cobre, as madeixas fivela acomoda, de ouro, e a maneira de a aljava da Lícia trazer sempre ao lado, ou como brande uma lança de mirto com ponta de ferro. ${ }^{17}$

Sobretudo os versos 812-814 enfatizam dois grupos de espectadores e sua reação frente à guerreira: "a juventude garrida e as mães velhas” que correm para contemplá-la; uma tal ênfase sugere que o leitor visualize a poesia em termos pictóricos, o que igualmente se aplica ao afresco da guerra de Troia presente nas paredes do templo de Juno em Cartago

16 "[...] the poet's eye is like the edited shot of a ciné-camera $[\ldots]$ ".

${ }^{17}$ Hos super advenit Volsca de gente Camilla / agmen agens equitum et florentes aere catervas, / bellatrix, non illa colo calathisve Minervae / femineas adsueta manus, sed proelia virgo / dura pati cursuque pedum praevertere ventos. / Illa vel intactae segetis per summa volaret / gramina nec teneras cursu laesisset aristas, / vel mare per medium fuctu suspensa tumenti / ferret iter celeris nec tingeret aequore plantas. / Illam omnis tectis agrisque effusa iuventus / turbaque miratur matrum et prospectat euntem, / attonitis inbians animis ut regius ostro / velet honos levis umeros, ut fibula crinem / auro internectat, Lyciam ut gerat ipsa pharetram / et pastoralem praefixa cuspide myrtum. 


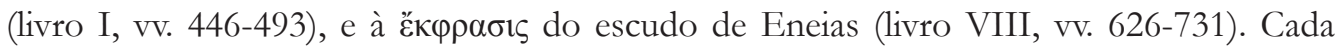
detalhe é importante como o seria em um quadro; não apenas as ideias e elementos que se encadeiam em uma narrativa racionalmente controlada, mas outrossim o efeito estético total é relevante. Boyd (1992, p. 223) denomina tal aspecto de "apelo emotivo", isolando-o como característica de Virgílio e, no que diz respeito a nosso estudo, uma das funções inovadoras de seu catálogo.

A cena final do trecho, a qual concomitantemente encerra o livro VII, com a descrição de Camila, é particularmente importante para argumentarmos neste sentido: Camila é vista pela fortuna crítica como um elemento estranho no corpo do texto (Boyd, 1992, p. 213). Primeiro, por ser a única personagem inventada do catálogo, porquanto todos os treze líderes tribais são ou históricos, ou mitológicos. ${ }^{18}$ Suas características em si sugerem um ser vivendo em uma zona intersticial entre o mundo real e o mito, dependendo de como entendemos as metáforas de Virgílio (livro VII, vv. 807 et seq.): ela é mais rápida que os ventos, flutua sobre o chão, sua beleza pasma os espectadores; ela não se assemelha em nada às amazonas da Cítia descritas por Heródoto, horrendas, bárbaras e mutiladas. ${ }^{19}$ Camila porta traços paradoxais: ${ }^{20}$ suas mãos delicadas empunham armas; o esplendor de suas vestes, a fivela de ouro que lhe adorna os cabelos parecem elementos antitéticos à aspera nirgo (livro XI, v. 664) vislumbrada em batalha.

Torrão (1993, p. 115) sinaliza que o caráter semidivino da guerreira é marcado pelo próprio Virgílio por três vezes no livro XI, ${ }^{21}$ boa parte a ela dedicado. Camila, todavia, encontra-se entre os que estão fadados à morte; sendo uma virgem vinculada à deusa Diana, a guerreira volsca é uma figura sem posteridade e, por extensão, seu protótipo é suprimido de Roma. Nessa chave, o catálogo de Virgílio coloca em contraste o que é aceitável e integra o mundo romano, e aquilo que deve ser dele extinto. A fórmula se repete logo no início do registro com o guerreiro que abre a narrativa das musas, Mezêncio, descrito como contemptor divum, um "desprezador das deidades do Olimpo" (livro VII, v. 648), fazendo oposição a Eneias, o pio (caracterização que remonta à Ilíada, canto XX, vv. 293 et seq).

Parece-nos, de todo modo, que é Camila quem traz em si o símbolo mais forte de caracterização nesta direção: parte de uma negociação de valores, ela é um ícone em que ideias importantes do classicismo augustano estão encapsuladas; a forma bela, sutil e bem medida. Mas a guerreira volsca também é um contraexemplo. Ela vive nos bosques, ao passo que o lugar da mulher romana é supostamente dentro de casa; para Boyd (1992, p. 216), o simples fato de Camila não ter habilidade ou vontade de costurar (cf. livro VII, vv. 804-805) já a distancia da aspiração romana de feminilidade, dos valores de gênero estabelecidos naquele universo. Além disso, Camila é uma guerreira, posição em si antagônica à de uma romana, passiva e resignada; ela se dedica a um ofício típico de homens em Roma. Nesse sentido, a

\footnotetext{
${ }^{18}$ Aparentemente esse não é um dado incontestado na fortuna crítica do autor: "that she is indeed invented has never [...] been seriously challenged [...]" (Horsfall, 2000, p. 519).

${ }^{19}$ Ver início do livro IV (Melpomene) das Histórias.

${ }^{20}$ Cf. Boyd, 1992, p. 220-221, 227.

${ }^{21}$ Cf. Eneida, livro XI, vv. 507; 699-701; 806.
} 
jovem que se porta como amazona, ao se rodear de uma corte feminina, não poderia figurar entre os ancestrais do povo romano, pois destoa do ideal requestado.

Se Virgílio enaltece suas qualidades, ao mesmo tempo traz críticas veladas a essa personagem "antinatural" e "antirromana", 22 as quais se constroem esparsamente, desde sua caracterização no livro VII, até o olhar detido sobre sua atuação em campo de batalha, no livro XI da Eneida. Torrão (1993, p. 118) destaca algumas destas críticas: para o autor, o pormenor da roupagem de Camila que encerra o livro VII avoca a vaidade, segundo ele, feminina "que pressagia o desenlace fatal", dado que a guerreira volsca padece por perseguir destemperadamente os ricos despojos de Cloreu (livro XI, vv. 780-782), sem perceber o guerreiro que está em seu encalço.

Acreditamos, no entanto, que tanto a menção ao manto de Camila quanto a reação que arrebata do público possui alguma ligação com o efeito causado por Jasão em seu manto nas Argonáuticas; ${ }^{23}$ há semelhança entre ambas as personagens, pois que, assim como a guerreira, Jasão aparece reluzente e encanta por seu aspecto, mas esconde por detrás da briosa carapaça uma figura débil, revestida de vezos malpropícios para o papel que desempenha (ou deveria desempenhar). O líder da expedição dos argonautas, afinal, depende dos ardis de uma mulher, a poderosa feiticeira Medeia, para sair vivo da região da Cólquida com seus comparsas, o que não podemos exatamente categorizar como atitude heroica no mundo antigo. Seja como for, o manto, de fato, parece ser uma crítica inicial de Virgílio à guerreira.

Um aspecto interessante sobre Camila sublinhado por Torrão (1993, p. 123), consiste no seguinte episódio: “enquanto criança e jovem caçadora, Camila envergava como vestuário uma simples pele de tigre", fato " apontado por Diana como um motivo de orgulho" (livro XI, vv. 576-577). Partindo da dicotomia entre a criança humilde e a soberba rainha dos volscos, podemos dizer que, mais do que vaidade, o que fomenta a libitina da hábil guerreira é sua v̋bprs. Ela extrapola limites e é gananciosa a ponto de morrer em decorrência da cupidez irresponsável como já se frisou; é precipitada (vv. 505-506), presunçosa (vv. 586-589), cruel na batalha (vv. 664-665) e escusadamente feroz (v. 709). Como bem observa Torrão (1993, p. 135), ela "é um exemplo vivo da uirtus latina que se apresenta como um padrão ainda imaturo de heroísmo e, por isso mesmo, está condenada a abortar"; as propriedades que ostenta não têm lugar na edificação da civilização vindoura, bem como as de outras personagens igualmente condenadas a desaparecer, caso do obstinado Turno e do covarde Arrunte, quem tira a vida de Camila pelas costas.

\section{CONSIDERAÇÕES FINAIS}

As inovações de Virgílio na tradição épica são diversas e se deixam ver mesmo em partes constitutivas mínimas, como é o caso do catálogo, elemento evidenciado no presente

\footnotetext{
${ }^{22}$ Cf. Boyd, 1992, p. 216.

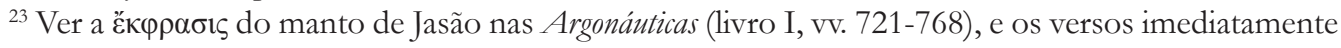
seguintes, em que as mulheres da cidade acorrem para admirá-lo, deslumbradas com sua aparência.
} 
estudo. Buscou-se mostrar que este seu registro, diferente do de Homero, é dotado de maior simetria e, na condição de momento retardador da narrativa, exerce uma função de transição dentro do poema; ele conecta harmonicamente duas partes a princípio díspares da Eneida, reforçando uma ideia central da obra: de que Eneias, um semideus, filho de Vênus, neto de Júpiter e predecessor de Otávio Augusto, está destinado a conquistar o Lácio, abrindo caminho para um glorioso Império de que os mais adequados farão parte. Virgílio o faz sem deixar de lado o uso elaborado de técnicas de descrição visual, esbanjando de detalhes pitorescos referentes a hábitos, vestimentas e regiões italianas, o que dota seu catálogo de caráter tanto político quanto estético acentuados; em toda sua beleza, o catálogo da Eneida cumpre o papel de preitear ao mesmo tempo o povo e o princeps senatus de Roma, ao enfatizar os valores do povo romano, ainda que por disparidade, como intercorre na caracterização de Turno e Camila, personagens que não encontram lugar na civilização promitente, cuja fundação se associa a um herói semidivino, e da qual Virgílio faz dimanar a poderosa Roma augustana.

\section{REFERÊNCIAS}

APOLLONIUS RHODIUS. The Argonantica. Trad. R. C. Seaton. London: The Loeb Classical Library, 1930.

BOYD, Barbara Weiden. Virgil's Camilla and the traditions of catalogue and ecphrasis (Aeneid 7.803-17). The American Journal of Philology, v. 113, n. 2, p. 213-234, Summer 1992.

FOWLER, W. Warde. Virgil's gathering of the clans. Observations on Aeneid VII, 601-817. Oxford: Blackwell, 1916.

GRANSDEN, K. W. Virgil: The Aeneid. Cambridge: Cambridge University Press, 2004.

HERODOTUS; THUCYDIDES. The Histories. Translation by George Rawlinson. Chicago; London: Encyclopedia Britannica, 1952. (Great books of the Western World, \#6)

HOMERO. Ilíada. Trad. Frederico Lourenço. São Paulo: Companhia das Letras; Penguin Books, 2013.

HOMERO. Odisseia. Trad. Frederico Lourenço. São Paulo: Companhia das Letras; Penguin Books, 2011.

HORSFALL, Nicholas. Virgil, Aeneid 7: a commentary. Leiden; Boston; Köln: Brill, 2000. (Mnemosyne, Bibliotheca Classica Batava. Supplementum; 198).

MARK, Samuel Eugene. Homeric Seafaring. College Station: Texas A\&M University Press, 2005.

MARTINS, Paulo. Imagem e Poder: Considerações sobre a Representação de Otávio Augusto. São Paulo: Editora da Universidade de São Paulo, 2011.

MILTON, John. English minor poems. Paradise Lost. Samson Agonistes. Areopagitica. Chicago; London: Encyclopedia Britannica, 1952. (Great Books of the Western World, \#32) 
PANOUSSI, Vassiliki. Aeneas' sacral authority. In: FARRELL, Joseph; PUTNAM, Michael C. J. (Ed.). A Companion to Vergil's Aeneid and its Tradition. Oxford: Blackwell Publishing, 2010. p. $52-65$.

TORRÃO, João Manuel Nunes. Camila, a virgem guerreira. Humanitas, Faculdade de Letras da Universidade de Coimbra, Instituto de Estudos Clássicos, v. 45, p. 113-136, 1993. Disponível em: <https://digitalis.uc.pt/es/artigo/camila_virgem_guerreira>. Acesso em: 26 jun. 2017. VIRGÍLIO. Eneida. Edição bilíngue. Trad. Carlos Alberto Nunes. Organização, apresentação e notas João Angelo Oliva Neto. São Paulo: Editora 34, 2014.

WILLIAMS, R. D. The function and structure of Virgil's catalogue in Aeneid 7. The Classical Quarterly, v. 11, n. 2, p. 146-153, Nov. 1961. 